\title{
Effects of Journaling Dietary Intake App on the Health Outcomes of Chronic Kidney Disease Stage 3B-5
}

\author{
Jei-Fuu Chen \\ National Taiwan University \\ d97725007@ntu.edu.tw
}

\author{
Ling-Ling $\mathrm{Wu}$ \\ National Taiwan University \\ 1lwu@management.ntu.edu.tw
}

\author{
Seng-Cho Chou \\ National Taiwan University \\ Chou@im.ntu.edu.tw
}

\begin{abstract}
The Dietary intervention is one of the major components of therapy for patients with chronic kidney disease (CKD), aiming to minimize uremic symptoms and to provide optimal nutritional status. For slowing the progression of renal failure, dietary protein restriction has been recommended for patients with $C K D$. However, receiving lower doses of this dietary intervention reduces its effectiveness and results in usage attrition and patient dropout. Therefore, dietary compliance has become a well-recognized challenge to the development of effective dietary protein restriction interventions. Using a food journaling app to log dietary intake has been shown to benefit people and health researchers. We hypothesized that using a food journaling app affects patients' dietary compliance (the first hypothesis), and indirectly improves health outcomes because of the increased compliance (the second hypothesis). We conducted a 12-week dietary protein restriction intervention. Twenty recruited participants were required to eat low-protein meals $(0.6 \mathrm{~g} / \mathrm{kg}$ ideal body weight/day), and self-report their dietary intake by using a food journaling app. Thirteen of 20 participants completed the dietary protein restriction intervention, and their health outcomes were measured according to changes in blood urea nitrogen, serum creatinine, albumin, and glycated hemoglobin compared with those who dropped out. The empirical results support the first hypothesis and show that using the food journaling app can significantly increase the dietary compliance, but the results regarding the second hypothesis were not significant.
\end{abstract}

\section{Introduction}

Chronic kidney disease (CKD) is a general term for heterogeneous disorders affecting the structure and function of the kidney, and is generally associated with old age, diabetes, hypertension, obesity, and cardiovascular disease [1]. Kidney failure is a worldwide public health problem, with increasing incidence and prevalence, high costs, and poor outcomes [2]. The early stages of CKD are often asymptomatic but can be detected during the assessment of comorbid disorders, and can be reversible. Rapidly progressive diseases can lead to kidney failure within months; however, most diseases evolve over decades and do not progress at the same rate, occasionally remaining in the same stage through many years of follow-up. The progressive nature of chronic kidney failure and the ensuing end-stage renal disease (ESRD) places a substantial burden on global health-care resources [3].

Dietary intervention involving a low-protein intake is one of the major components of therapy for patients with CKD, aiming to minimize uremic symptoms and provide optimal nutritional status. Experimental studies have suggested that a low-protein intake may prevent the natural progression of CKD towards ESRD, thus delaying the need for maintenance dialysis treatment [4]. For slowing the progression of renal failure, people with CKD must track their intake of certain nutrients (particularly sodium, potassium, and fluids) carefully. Protein-restricted meals $(0.6 \mathrm{~g} / \mathrm{kg}$ ideal body weight/day) have been recommended for patients with moderate to severe CKD [5].

Dietary adjustments for patients with CKD are complex; nurses collaborate with dieticians to help patients self-manage their diet and fluid intake by using educational materials such as brochures, fact sheets, lists of foods to avoid, referrals to Internet sites, and ongoing counseling. Despite these efforts, patients continue to exhibit poor dietary compliance [6]. Studies [7-9] have shown that, when these diets are not strictly adhered to, they are markedly less effective. Patient compliance with low-protein diets has become a well-recognized challenge to the development of effective dietary protein restriction interventions.

Self-management is the ability to "manage the symptoms, treatment, physical, psychosocial, cultural, and spiritual consequences and inherent lifestyle changes required for living with a long-term chronic 
disease" [10]. Self-monitoring, defined as awareness and recording of information that varies with daily routines [11], is one aspect of self-management [12].

Food journaling apps in smartphones have been shown to help patients self-monitor their dietary intake. Smartphones, being personal devices that people typically keep with or near them, can provide relevant information and decision support required by patients. A food journaling app enables people to self-monitor their intake by providing a means to recording what they have eaten. Food journaling apps for patients with CKD can empower patients to make improved food choices by enabling them to compare their intakes of protein, phosphorus, potassium and fluids, with those of their nutrition prescriptions [13].

Searching the Apple's App Store for "nutrition", and "kidney" yielded 2,573 applications and 214 applications, respectively. Searching with the same terms in the Google Play Store yielded at least 1,000 results for each term. Most of the food journaling apps enable patients to input their nutrition prescription, compare their daily intakes with those of their prescription, and search a database for the nutrition information for a particular food item. Lists of recommended foods categorized by meal or portion size information may also be available. Although previous effort to develop for food journaling apps for patients with CKD have been productive, however, to the best of our knowledge, none of the food journaling apps have effectively overcome the challenges users face when logging their dietary intake; the effort required to create food entries is high compared to the perceived self-benefit of self-monitoring food intake.

To address this problem, we conducted a 12 -weeklong physician-supervised dietary protein restriction intervention, which provided dietitian-supervised precooked frozen low-protein diet (LPD) meal boxes to the participants. We developed an android food journaling app for self-monitoring this intervention. Rather than asking participants to log every simple type of food individually in a database-lookup diary, we simplified the logging procedure by delivering LPD meal boxes to control the participants' daily protein intake, thus minimizing the effort required to create food entries and facilitating the long-term use of the food journaling app. We asked the participants to log information about the amount of food they had not completely consumed, which might cause insufficient daily nutrition intake. Furthermore, we focused on the participants' entries on any extra food consumed, the intake of which we recommended against as it might increase damage to the kidneys. We considered the entries on incompletely consumed LPD meals and extra food consumed as patient compliance with dietary intake self-monitoring using the food journaling app

The contributions of this study are twofold. First, we developed a simplified self-monitoring food journaling app for evaluating the adherence of users to the prescribed diet in health interventions. Second, we report a usability study associated with a dietary protein restriction intervention study in which we provided LPD meals ( $0.6 \mathrm{~g}$ protein $/ \mathrm{kg}$ ideal body weight/day) to patients with stage $3 \mathrm{~b}, 4$, and 5 chronic kidney disease (CKD) to evaluate the effect of metabolic condition, progression, and patient compliance with dietary intake self-monitoring by using the food journaling app on improving health outcomes.

\section{Literature review}

\subsection{Chronic Kidney Disease}

Normal kidney function involves fluid regulation (including electrolyte balance) and the filtration of waste products (primarily urea), and plays a role in endocrine functions of systems such as red blood cell production and bone metabolism. Each kidney has millions of nephrons containing smaller structural units called glomeruli. Many patients with CKD do not know they have it; the undamaged glomeruli adapt and maintain normal laboratory parameters even when more than two-thirds of nephrons are no longer viable. People born with a single kidney are often unaware of it and are not at a higher risk of kidney disease.

CKD was formally classified into five stages under the 2003 Kidney Disease Outcomes Quality Initiative (K/DOQI) as shown in Table 1. Prior to this initiative, no uniform criteria for the diagnosis and base care of CKD existed. Stages 1-4 represent kidney disease categories in which medical and nutritional management can affect and potentially delay progression to Stage 5 (chronic kidney failure). Over time, CKD reduces the number of functioning nephrons, overloads the remaining nephrons, and eventually may lead to kidney failure. Normal kidney function - GFR above $90 \mathrm{~mL} / \mathrm{min} / 1.73 \mathrm{~m}^{2}$ and no proteinuria.

Table 1. Classification stages of chronic kidney disease

\begin{tabular}{|c|l|c|}
\hline Stage & Description & $\begin{array}{c}\mathrm{GFR}^{\mathrm{a}} \\
(\mathrm{mL} / \mathrm{min} / 1.73 \\
\left.\mathrm{m}^{2}\right)\end{array}$ \\
\hline 1 & $\begin{array}{l}\text { Kidney damage with } \\
\text { normal or increased GFR }\end{array}$ & $\geq 90$ \\
\hline 2 & $\begin{array}{l}\text { Kidney damage with } \\
\text { mild decreased GFR }\end{array}$ & $60-89$ \\
\hline 3 & Moderate decreased GFR & $30-59$ \\
\hline
\end{tabular}




\begin{tabular}{|c|l|c|}
\hline 4 & Severe decreased GFR & $15-29$ \\
\hline 5 & Kidney failure & $<15$ or dialysis \\
\hline
\end{tabular}

${ }^{\mathrm{a}}$ GFR (glomerular filtration rate) estimated from serum creatinine using MDRD (Modification of Diet in Renal Disease) study equation based on age, sex, race, and calibration for serum creatinine [14].

Dietary intervention, which aims to minimize uremic symptoms and provide optimal nutrition, is one of the major components of therapy for patients with CKD. A "Western" adult diet provides approximately $1.35 \mathrm{~g}$ protein $/ \mathrm{kg}$ body weight/day. The required daily protein intake for women is $35-50 \%$ lower than that of men of the same age [15]. The most recently issued standards set a threshold of a "safe" protein intake of $0.8 \mathrm{~g}$ protein $/ \mathrm{kg}$ body weight/day, for ensuring that $97.5 \%$ of people will be in "protein balance", This intake includes protein from mixed vegetal and animal sources [16-17]. To limit the accumulation of nitrogenous waste products and slow the progression of renal failure, protein restriction has been recommended for patients with moderate to severe CKD [18]. Various dietary regimens have been proposed: a conventional low-protein diet (LPD) providing $0.6 \mathrm{~g}$ protein/kg body weight/day.

\subsection{Adherence to Internet-based Healthy Behaviour Interventions}

Globally, the incidence of lifestyle diseases, such as kidney diseases, diabetes, obesity, and cardiovascular diseases, are increasing. At least $50 \%$ of all cancers are considered preventable by adopting healthy behaviors and avoiding unhealthy practices [19]. Obesity is a risk factor for kidney diseases, cardiovascular diseases, diabetes, and cancer; furthermore, the risk of these diseases is influenced by the types of food consumed. In addition to balancing the caloric intake, the American Heart Association recommends preventing cardiovascular diseases by consuming a diet rich in fruits and vegetables and whole grain-high fiber, limiting saturated fat intake, and reducing consumption of added sugars and alcohol [20]. Similar recommendations are offered for preventing diabetes [21].

Mobile application technologies have the potential to be used as a medium in health behavior change programs [22]. Internet-based health behavior interventions minimize face-to-face interactions, thereby increasing cost effectiveness by increasing accessibility [23]. Such interventions can induce behavioral changes for multiple health conditions [24$25]$, thus improving such health outcomes as increased weight loss [26], reduced smoking [27], increased physical activity [28-29], dietary changes (e.g., increase in fruit and vegetable consumption) [30], and a slower decline in health.

Siek, Connelly, \& Rogers et al. explored PDAbased self-monitoring of dietary intake by patients with CKD. They examined challenges faced by people when recording information and reported that patients attempting to change their nutrition behaviors to treat a disease may be more motivated by using technology to support self-monitoring than are patients focused on preventing the disease [31-32]. Andrew, Borriello, and Fogarty compared the user performance and preferences of three food dairies: a conventional database-lookup diary, a diary tracking only food groups, and a diary tracking food groups and some nutrients. They reported that users preferred either the conventional approach or the food groups and nutrients approach [33].

Recent studies have shown that Internet-based health behavior interventions can improve health outcomes through users' behavioral changes [34-36]. However, formal research and informal feedback indicate that people face difficulties in adhering to Internet- or smartphone-based health behavior intervention for extended periods of time [37]. Therefore, dietary compliance has become a major challenge in developing effective dietary protein restriction interventions. We examined the effect of a smartphone food journaling app developed on dietary compliance to address a common challenge users report when using food diaries on their mobile phones; the effort required to create food entries is high compared to the perceived self-benefit of selfmonitoring food intake. Our first hypothesis is as follows:

- H1. Use of a food journaling app considerably increases the dietary compliance of patients undergoing dietary protein restriction interventions.

\subsection{Cognitive Behaviour Therapy}

Behavior is affected by a complex set of factors, many of which are psychological. Thus, psychological approaches, such as cognitive behavior therapy (CBT), are a commonly used and effective form of therapy for a wide range of psychological disorders, including depression and anxiety disorders [38]. CBT is based on a combination of basic behavioral and cognitive principles and is most closely allied with the scientistpractitioner model, in which clinical practice and research is driven by a scientific perspective, clear operationalization of the problem, and an emphasis on 
measurement, including measuring changes in cognition, behavior, and attainment of goals.

Studies have reported that the effectiveness of Internet-based interventions is highly affected by nonusage attrition [39]. Christensen, Griffiths, and Korten [40] observed that the efficacy trials of Internet-based interventions show satisfactory-to-excellent levels of adherence. Open-access websites have been associated with poor adherence and dropout, with a substantial number of users not completing all modules and closing the website before completing the program. For example, Farvolden, Denisoff, and Selby et al. [41] observed that only $1 \%$ of the participants completed a 12-week open-access program. Couper, Alexander, and Zhang [42] observed that a higher level of engagement is associated with participant retention and a positive change in the major outcome of the intervention designed to promote consumption of fruits and vegetables. As suggested by Wicks, Massagli, and Frost [43], patients who used more features of the online health community website PatientsLikeMe perceived considerable benefits on treatment decisions, symptom management, clinical management, and outcomes.

The increasing Internet penetration offers new treatment opportunities. CBT is extremely suitable for adaption to a computer-based format. CBT is a structured treatment approach for developing new types of behavior and cognition. A central element in CBT is self-monitoring, that is, participants observe and record their own behavior, identify the factors that affect their behaviors or create problems, make changes in their daily habits, and monitor the effects of these changes [44]. Regular self-monitoring has many advantages, such as increasing self-knowledge and providing valuable information on the effects of interventions.

In this study, we requested participants to attend one clinic appointment every month. A team comprised of nephrologists and dietitians observed the participants and handed out an assignment: complete their food diary and refrain from consuming food apart from the meal boxes delivered to them.

We examined the effect of a smartphone food journaling app developed on improving health outcomes indirectly through increasing dietary compliance in dietary protein restriction intervention. Our second hypothesis is as follows:

- H2. Use of the food journaling app considerably improves health outcomes indirectly through increasing dietary compliance in dietary protein restriction interventions.
The research model in Figure 1 illustrates hypotheses 1 and 2 .

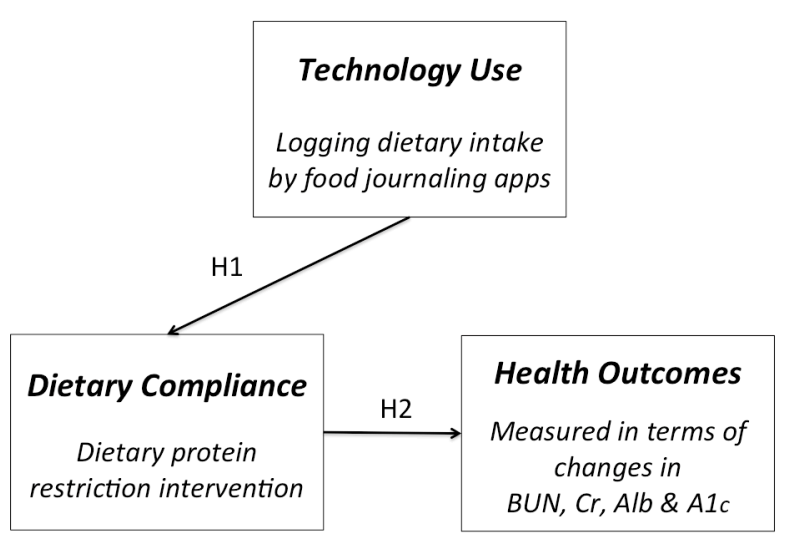

Figure 1. Research Model

\section{METHOD}

\subsection{Design of the Food Journaling APP}

This section presents the designing of the CareMe food journaling app, a smartphone food diary for patients with CKD. It was developed by CareMe.tw (Figure 2).

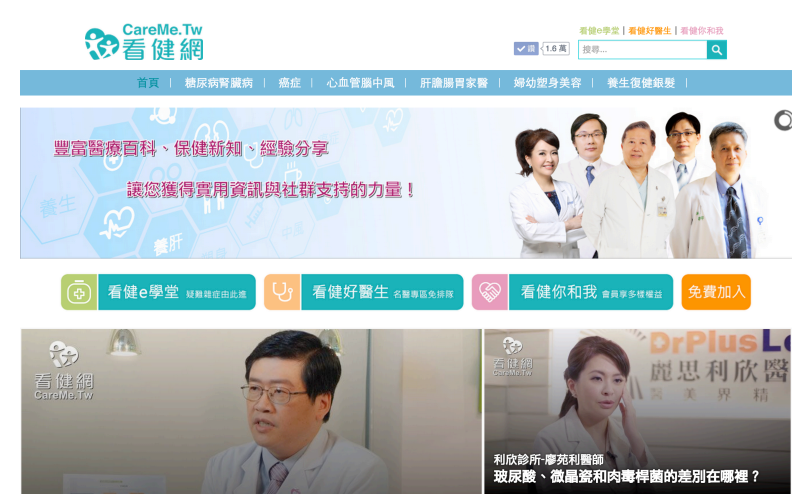

Figure 2: A screenshot of the CareMe.tw website.

CareMe.tw functions as a medical knowledge base; new medical information bulletin board; and a selfmanaging, self-monitoring, social networking, and experience-sharing platform. CareMe.tw aims to provide crucial medical information and social support for the public and patients and their families.

CareMe.tw has information on cancer, cardiovascular diseases, stroke, diabetes, kidney diseases, allergy immunity, elderly medicine, and maternal, women, and child healthcare. CareMe.tw invites professional physicians, nurses, nutritionists, and fitness trainers to participate in our interviews to provide useful and accurate first-hand information through videos. Without queuing in or making an 
appointment with a local clinic, medical knowledge can now be received from well-known doctors through CareMe.tw.

CareMe Food Journaling App is a smartphone App developed for a specific dietary protein restriction intervention, and uses most functions available at CareMe.tw; in addition, it assists users in capturing and documenting food consumption incidents throughout the day. CareMe Food Journaling App was to address a common challenge users report when using feed diaries on their mobile phones; the effort required to create food entries is high compared to the perceived selfbenefit of self-monitoring food intake.

Twenty participants were instructed to consume two LPD meals every day, which provided $0.6 \mathrm{~g}$ protein/kg body weight/day, for three months. All LPD meals were precooked and delivered as frozen meal boxes to participants' homes. CareMe Food Journaling App explores the value of reducing the time and effort required to capture a food consumption incident in addition to reducing the amount of detail captured. After participants consume the LPD meals daily, they must report the status of their food consumption. When participants open the app, it automatically directs them to a section on the type of meal consumed. Participants must report the amount of meal consumed and the type and amount of food not consumed. After completing the main report section, participants must report any extra food consumed. The CareMe food journaling app was designed to simplify inputting the dietary intake (Figure 3).
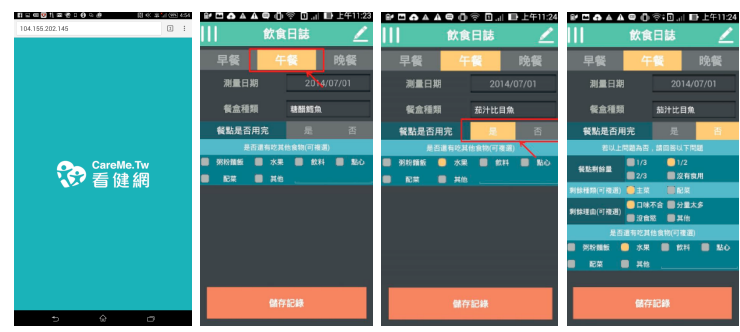

Figure 3: Screenshots of the CareMe food journaling app. 1. Open the app. 2. The app automatically directs the participants to a section on the type of meal consumed. 3. Report the amount of food consumed. 4. Report any extra food consumed.

Features not described in this paper include medical knowledge base, new medical information bulletin board, and social networking and experience-sharing features.

\subsection{Procedures}

The study was performed with patients with CKD who were being treated at a nephrology hospital at Hsinchu, Taiwan. Twenty patients were selected after they satisfied the clinical inclusion criteria. A multidisciplinary team consisting of a consultant nephrologist and a team of dietitians delivered the program. A pharmacist and renal transplant coordinator assisted as necessary. After meeting the inclusion criteria (Table 2) and providing informed written consent, all the patients were instructed to eat two lowprotein diet meals everyday for 3 months $(0.6 \mathrm{~g} / \mathrm{kg}$ ideal body weight/day).

Table 2. Population Inclusion Criterion

\begin{tabular}{|l|l|}
\hline 1 & Age $\geq 50$ years \\
\hline & $\begin{array}{l}\text { A baseline of estimated GFR (eGFR) between } \\
15 \text { and } 29 \mathrm{ml} / \mathrm{min} / 1,73 \mathrm{~m} 2, \text { that had to remain } \\
\text { stable during } 3 \text { consecutive controls (eGFR } \\
\text { variability }<15 \% \text { ) }\end{array}$ \\
\hline & $\begin{array}{l}\text { The subject is able to understand and comply } \\
\text { with protocol requirements, instructions and } \\
\text { protocol-stated restrictions. }\end{array}$ \\
\hline 4 & $\begin{array}{l}\text { The subject and/or subject's primary caregiver } \\
\text { is able to use computer, smartphone and } \\
\text { Internet }\end{array}$ \\
\hline
\end{tabular}

The patients also were required to attend one clinical appointment per month for 3 months. The dietitian and nephrologist saw them at each appointment. Heath outcomes data were collected at the first visit (baseline), and at the end of the study. The patients initially attended a group information session were provided with a smartphone with a diet food journaling app preinstalled. The program instructor taught patients how to use the food journaling app to self-report their dietary intake in the session. Patients need to self-report every meals they had, and also self-report any additional food they have intake during the research. Each patient in the program was encouraged to comply with the dietary plans as prescribed.

Subject demographics of this research are shown in the Table 3 . Twenty men and women were recruited for this study. Throughout the 12 weeks of the program, seven participants quit or were unable to continue for other reasons (dropout group). 13 participants completed the program (retained group). 
Table 3. Demographics data of participants

\begin{tabular}{|l|r|}
\hline \multicolumn{1}{|c|}{ Participants } & All Participants $(\mathrm{n}=20)$ \\
\hline Gender : Female & $9(45 \%)$ \\
\hline Male & $11(55 \%)$ \\
\hline $\begin{array}{l}\text { Blood urea } \\
\text { nitrogen (BUN) }\end{array}$ & $60.81\left(30.27^{\mathrm{a}}\right) \mathrm{mg} / \mathrm{dL}$ \\
\hline $\begin{array}{l}\text { Serum Creatinine } \\
(\mathrm{Cr})\end{array}$ & $4.02\left(2.44^{\mathrm{a}}\right) \mathrm{mg} / \mathrm{dL}$ \\
\hline Albumin (Alb) & $4.22\left(0.35^{\mathrm{a}}\right) \mathrm{g} / \mathrm{dL}$ \\
\hline $\begin{array}{l}\text { Glycated } \\
\text { hemoglobin } \\
(\text { A1c) }\end{array}$ & $6.84\left(1.48^{\mathrm{a}}\right) \%$ \\
\hline Stage 3b $: 4: 5$ & $2(10 \%): 12(60 \%): 6(30 \%)$ \\
\hline
\end{tabular}

a Mean (Standard Deviation).

\subsection{Protein restriction intervention program for patients with CKD}

In our study, patients who joined the intervention had to eat two dietary protein restriction meals ( 0.6 $\mathrm{g} / \mathrm{kg}$ ideal body weight/day) a day, lunch and dinner, during the course of the study. The patients had to selfreport every low-protein meal they ate and any additional food they consumed.

\subsection{Measures}

At the beginning of the program, we measured the participants' blood urea nitrogen (BUN), serum creatinine (Cr), albumin (Alb) and glycated hemoglobin (A1c) at baseline. We also measured their health outcomes after the program ended as checking the variances. The participants' intake of low-protein meals and engagement in using the food journaling app were also recorded and indicated their retention to the program.

\subsubsection{Blood urea nitrogen (BUN):}

The liver produces urea in the urea cycle as a waste product of the protein digestion. Normal human adult blood should contain between 6 to $20 \mathrm{mg}$ of urea nitrogen per $100 \mathrm{~mL}(6-20 \mathrm{mg} / \mathrm{dL})$ of blood.

\subsubsection{Serum Creatinine (Cr):}

Creatinine is a chemical waste molecule that is generated from muscle metabolism. It is a chemical molecule that is present in the serum (liquid portion) of the blood and is produced from another molecule, creatine, which is a component of muscle.

\subsubsection{Albumin (Alb):}

The albumins are a family of globular proteins, the most common of which is serum albumin. The albumin family consists of all proteins that are water-soluble, are moderately soluble in concentrated salt solutions, and experience heat denaturation. Albumins are commonly found in blood plasma and are unique from other blood proteins in that they are not glycosylated.

\subsubsection{Glycated hemoglobin (A1c):}

Glycated hemoglobin (hemoglobin A1c, HbA1c, $\mathrm{A} 1 \mathrm{C}$, or Hb1c; sometimes also HbA1c or HGBA1C) is a form of hemoglobin that is measured primarily to identify the average plasma glucose concentration over prolonged periods of time. It is formed in a nonenzymatic glycation pathway by the exposure of hemoglobin to plasma glucose. Normal levels of glucose produce a normal amount of glycated hemoglobin. As the average amount of plasma glucose increases, the fraction of glycated hemoglobin increases in a predictable way. This serves as a marker for average blood glucose levels over the previous 3 months prior to the measurement because this is the half-life of red blood cells.

\subsubsection{Dietary compliance when using the food journaling app}

Technology use was an independent variable to the dependent variables of patient compliance with the low-protein meals. Technology use was also used as the mediator variable between dietary compliance and health outcomes. We requested that the participants self-report their data at every meal possible. Participants whose self-report rates were less than $90 \%$, they were classified as belonging to the dropout group. Participants who self-reported more than $90 \%$ of their meals throughout the program were classified as belonging to the retained group.

\subsubsection{Patient compliance in dietary protein restriction intervention}

In medicine, compliance describes the degree to which a patient correctly follows medical advice. Most commonly, it refers to medication or drug compliance, but it can also apply to other situations such as medical device use, self-care, self-directed exercises, and therapy sessions. Both the patient and the health-care provider affect compliance, and a positive physicianpatient relationship is the most crucial factor in improving compliance. We took participants' entries of 
incompletion portion of LPD meals and extra foods have eaten as patient compliance of dietary intake selfmonitoring by the food journaling app.

\subsection{Statistical analysis}

All data are expressed as means (standard deviation). We compared comparisons between the retained and dropout groups measured at the beginning and end of the 12 weeks program by using ANOVA on a given variable with a corresponding $95 \%$ confidence intervals. We performed statistical analysis by using the software packages SPSS for Windows (Version $7.0)$.

\subsection{Ethics}

All the participants signed an informed consent form before participating in this study.

\section{Empirical results}

\subsection{Effects of technology use on dietary compliance}

We conducted a 12-week-long physiciansupervised dietary protein restriction intervention, which delivered dietitian-supervised pre-cooked frozen low-protein diet (LPD) meal boxes to participants. A food journaling app that specifically designed for selfmonitoring this dietary protein restriction intervention.

Twenty participants were recruited. The dietary intervention group was required to eat low-protein meals $(0.6 \mathrm{~g} / \mathrm{kg}$ ideal body weight/day) throughout the study. Smartphones with a food journaling app specifically designed for this health intervention were issued to all the participants for self-monitoring their food intake. After 12 weeks, 13 out of 20 participants were completed the intervention (retained group), their self-report completion ratio were measured in compare to the self-report completion ratio of another 7 participants did not complete the program (dropout group).

In $\mathrm{H} 1$, we proposed that using a food journaling app significantly increases the dietary compliance of participants in protein restriction interventions. The relationship between app usage and program adherence is positive and significant at the result $(\mathrm{F}[1,18]=$ $78.399, \mathrm{p}=0.00$, see Table 4), suggesting that the retained group demonstrated significantly greater technology use compared with the dropout group, thus supporting $\mathrm{H} 1$.
Table 4. Technology Use differences of retained and dropout groups at the intervention

\begin{tabular}{|l|l|l|l|l|}
\hline $\begin{array}{l}\text { All } \\
\text { Participants } \\
(\mathrm{n}=20)\end{array}$ & $\begin{array}{l}\text { Retained } \\
\text { Group } \\
(\mathrm{n}=13)\end{array}$ & $\begin{array}{l}\text { Dropout } \\
\text { Group } \\
(\mathrm{n}=7)\end{array}$ & $\begin{array}{l}\text { Retained } \\
\text { Group vs. } \\
\text { change in } \\
\text { Dropout } \\
\text { Group }\end{array}$ \\
\hline $\begin{array}{l}\text { Technology } \\
\text { Use }\end{array}$ & $\begin{array}{l}96.75 \% \\
(3.03 \%)\end{array}$ & $\begin{array}{l}61.64 \% \\
(14.00 \%)\end{array}$ & 78.39 & \multicolumn{2}{|c|}{0.00} \\
\hline
\end{tabular}

${ }^{\mathrm{a}}$ Data expressed as Mean (Standard Deviation).

${ }^{\mathrm{b}}$ Technology use in terms of Self-Report completion ratio as two self-reports a day in 12 weeks. ${ }^{*} p<.05,{ }^{* *} p<.01,{ }^{* * *} p<.001$

\subsection{Using the food journaling app significantly improves health outcomes indirectly through increasing dietary compliance in dietary protein restriction intervention}

In $\mathrm{H} 2$, we proposed that using a food journaling app indirectly improves the health outcomes indirectly by improving dietary compliance in protein restriction interventions.

We requested 20 participants to self-report every meals they had, and also self-report any additional food they have intake during the research. Each patient in the program was encouraged to comply with the dietary plans as prescribed. Thirteen of 20 participants were completed the 12-week intervention (retained group) their health outcomes were measured according to changes in Blood Urea Nitrogen (BUN), Serum Creatinine (Cr), Albumin (Alb), and Glycated Hemoglobin (A1c) and compared with those of the other seven participants who were unable to continue the program (dropout group).

The difference in BUN change the retained group and dropout groups was not significant $(F[1,18]=$ 1.691, $\mathrm{p}=0.210)$. The difference in $\mathrm{Cr}$ changes between the retained and dropout groups was not significant $(F[1,18]=0.011, p=0.918)$. The difference in Alb changes between the retained and dropout group was not significant $(F[1,18]=0.128, p=0.725)$ and the difference in A1c changes between the retained and dropout groups was not significant $(F[1,18]=0.754, p$ $=0.397)$. Although the BUN changes in the retained group were smaller than those in the dropout group (11.40 [11.47] vs. 15.57 [15.46]), the Alb changes in the retained group were smaller than those in the dropout group (0.15 [0.16] vs. 0.16 [0.26]) Therefore, $\mathrm{H} 2$ is not supported. (Table 5.) 
Table 5. Changes of health outcomes in the Retained group vs. Dropout group

\begin{tabular}{|c|c|c|c|c|}
\hline & $\begin{array}{l}\text { Retained } \\
\text { Group } \\
(n=13)\end{array}$ & $\begin{array}{l}\text { Dropout } \\
\text { Group } \\
(n=7)\end{array}$ & \multicolumn{2}{|c|}{$\begin{array}{l}\text { Retained Group } \\
\text { vs. Dropout } \\
\text { Group }\end{array}$} \\
\hline & Change & Change & $\begin{array}{l}\text { F- } \\
\text { value }\end{array}$ & $p$-value ${ }^{b}$ \\
\hline BUN & $\begin{array}{l}11.40 \\
(11.47)\end{array}$ & $\begin{array}{l}16.13^{\mathrm{a}} \\
(25.50)\end{array}$ & 1.691 & 0.210 \\
\hline $\mathrm{Cr}$ & $\begin{array}{l}0.54 \\
(0.68)\end{array}$ & $\begin{array}{l}0.54 \\
(0.84)\end{array}$ & 0.011 & 0.918 \\
\hline Alb & $\begin{array}{l}0.15 \\
(0.16)\end{array}$ & $\begin{array}{l}0.16 \\
(0.26)\end{array}$ & 0.128 & 0.725 \\
\hline A1c & $\begin{array}{l}0.84 \\
(0.83)\end{array}$ & $\begin{array}{l}0.28 \\
(0.46)\end{array}$ & 0.754 & 0.397 \\
\hline
\end{tabular}

${ }^{a}$ Data expressed as Mean (Standard Deviation).

${ }^{*} p<.05,{ }^{* *} p<.01,{ }^{* * *} p<.001$

\subsection{Feedback from the participants}

Table 6. Comments on APP design and comparing APP with paper diet log

\begin{tabular}{|c|l|l|}
\hline Age & $\begin{array}{l}\text { Comments on APP } \\
\text { Design }\end{array}$ & $\begin{array}{l}\text { Comparing App with } \\
\text { paper diet log }\end{array}$ \\
\hline 46 & $\begin{array}{l}\text { OK, it's good for } \\
\text { me to use }\end{array}$ & $\begin{array}{l}\text { App is better, since } \\
\text { it's portable }\end{array}$ \\
\hline 42 & $\begin{array}{l}\text { Good to use for me } \\
\text { Didn't take too much } \\
\text { time to log, } \\
\text { convenient to use }\end{array}$ \\
\hline 41 & $\begin{array}{l}\text { It's new to use, but } \\
\text { convenient to keep } \\
\text { log }\end{array}$ & $\begin{array}{l}\text { App is better } \\
\text { convenient to use }\end{array}$ \\
\hline 45 & $\begin{array}{l}\text { Good to use App, } \\
\text { convenient to me }\end{array}$ & $\begin{array}{l}\text { App is better, portable } \\
\text { and all items are in } \\
\text { there, no need to write }\end{array}$ \\
\hline 71 & $\begin{array}{l}\text { Answered by his } \\
\text { daughter) } \\
\text { App is good to use } \\
\text { for her to help his } \\
\text { father, the patient is } \\
\text { too old to use cell }\end{array}$ & $\begin{array}{l}\text { App is better, portable } \\
\text { and can be remotely } \\
\text { to record it after } \\
\text { phone conversation } \\
\text { with her father }\end{array}$ \\
\hline
\end{tabular}

Table 7. Comments on dietary protein restriction intervention

\begin{tabular}{|c|c|}
\hline Age & $\begin{array}{l}\text { Comments on dietary protein restriction } \\
\text { intervention }\end{array}$ \\
\hline 46 & $\begin{array}{l}\text { 1. Meals helped me stable at my disease } \\
\text { condition }\end{array}$ \\
& $\begin{array}{l}\text { 2. I don't need to think about what to eat or } \\
\text { to prepare to comply with my condition } \\
\text { requirement. }\end{array}$ \\
\hline 42 & 1. Help at my weight control. \\
\hline
\end{tabular}

\begin{tabular}{|c|c|}
\hline & $\begin{array}{l}\text { 2. Regular meals (calorie, limited foods), } \\
\text { good to control diet. }\end{array}$ \\
\hline 54 & $\begin{array}{l}\text { 1. Convenient to eat, save time. } \\
\text { 2. If it can add pictures on App, it will be } \\
\text { good to use pictures for selection rather } \\
\text { than text. } \\
\text { 3. I would like to join again if such. clinical } \\
\text { trial will be held again. }\end{array}$ \\
\hline 41 & $\begin{array}{l}\text { 1. Convenient to send to home, flexible } \\
\text { time to re-heat and eat. }\end{array}$ \\
\hline 45 & $\begin{array}{l}\text { 1. 1. Help me having meal regularly. } \\
\text { 2. Improved me at bio-data. } \\
\text { 3. Monitor and motivate me to have right } \\
\text { foods. }\end{array}$ \\
\hline 71 & $\begin{array}{l}\text { 1. (Answered by his daughter) Help to } \\
\text { control condition }\end{array}$ \\
\hline
\end{tabular}

\section{Discussion and implications}

\subsection{Conclusion}

Our results show that increased use of using of a food journaling app in dietary intervention can improve patient compliance. These results are similar to those of Siek, Connelly \& Rogers et al. [45], in that patients who must change nutrition behaviors to treat their CKD may be more motivated to use technology to support self-monitoring. They examined the time and frequency of entries, the challenges patients faced, and the use of barcode scanners and voice input to improve food entry in order to facilitate patient self-reporting.

Increased dietary compliance improved the health outcomes of dietary interventions in the current study. The results suggest that using a food journaling app may not able to help explain why health outcomes improved, thus achieving enhanced health outcomes when a food journaling app is used. In addition, our study raises a concern that merits further study: Most existing food journaling apps enable patients only to search a database for nutrition information or provide lists of recommended food according to meal or portion size. None of the apps enable patients to simply input their daily nutritional intake for comparison with their prescribed diet. Because using a food journaling app can improve dietary compliance, could a new feature of a food journaling app with increasing social capital increase the effects of dietary compliance and thus improve health results? Furthermore, could having social capital provide benefits to users even after a dietary intervention ends? Finally, could online health communities help users adhere to their dietary intake restrictions for a longer period? 


\subsection{Limitations and future research}

Limitations inherent in the study design that should be noted. First, the requirement that participation eligibility include both attending to the retained group and dropout group has being an active user at smartphone applications. Therefore, the findings may not apply to all users. Second, not all the participants may have enjoyed the low-protein meals provided by the study. This might have influenced the dropout rate, because the participants were required to eat only the low-protein meals throughout the study.

Furthermore, the effort expended to retain participants (the study nurse' s phone tracking and email reminders) may limit the generalizability of our results to other interventions. In addition, the food journaling app is not all-inclusive, because of the rapid improvements being made in this type of health intervention. There might be merging features that were not been included in this app but could be included in future research. For example, the question remains whether social support could be implemented by mobile applications on smartphones or tablets. Participants may benefit more by sharing health-related information in an online health community via smartphones and by allowing other users can see and response.

\subsection{Managerial implications}

In conclusion, our study suggests that using a food journaling app significantly increases participant dietary compliance in protein restriction interventions. However, the health outcomes between the retained and dropout groups showed no significant differences. Our results suggest that when patients receive dietary intervention that entails using a food journaling app, they may be able to maintain a more stable BUN, Cr, $\mathrm{Alb}$ and A1c for extended periods of time. Our findings can be applied to the designs of the next generation food journaling apps, which could include new features, and enable users to self-report their dietary intake. Our findings might be useful to researchers planning, health interventions for other chronic diseases such as diabetes, cardiovascular disease and stroke.

\section{References}

[1] Levey, Andrew S., and Josef Coresh. (2012). "Chronic kidney disease." The Lancet 379.9811: 165-180.

[2] Eknoyan G, Lameire N, Barsoum R, et al. (2004). The burden of kidney disease: Improving global outcomes. Kidney Int 66:1310-1314.
[3] El Nahas, A. Meguid, and Aminu K. Bello. (2005). "Chronic kidney disease: the global challenge." The Lancet 365.9456: 331-340.

[4] Klahr S, Levey AS, Beck GJ, Caggiula AW, Hunsicker L, Kusek JW, et al. (1994). The effects of dietary protein restriction and blood pressure control on the progression of chronic renal disease. Modification of Diet in Renal Disease Study Group. New England Journal of Medicin;330(13):87784.

[5] Feiten, S. F., et al. (2005). "Short-term effects of a verylow-protein diet supplemented with ketoacids in nondialyzed chronic kidney disease patients." European journal of clinical nutrition 59.1: 129-136.

[6] Denhaerynck K, Manhaeve D, Dobbels F, Garzoni D, Nolte C, De Geest S. Prevalence and consequences of nonadherence to hemodialysis regimens. (2007). American Journal of Critical Care; 16:222-235.

[7] Glasgow RE, Christiansen SM, Kurz D, King DK, Woolley T, Faber AJ, et al. (2011). Engagement in a diabetes self-management website: usage patterns and generalizability of program use. J Med Internet Res;13(1):e9

[8] Leslie E, Marshall AL, Owen N, Bauman A. (2005). Engagement and retention of participants in a physical activity website. Prev Med;40(1):54-59.

[9] Strecher VJ, McClure J, Alexander G, Chakraborty B, Nair V, Konkel J, et al. (2008). The role of engagement in a tailored web-based smoking cessation program: randomized controlled trial. J Med Internet Res;10(5):e36.

[10] Wilkinson A, Whitehead L. (2009). Evolution of the concept of self-care and implications for nurses: A literature review. International Journal of Nursing Studies; 46:11431147.

[11] Wilde M, Garvin S. (2007). A concept analysis of selfmonitoring. Journal of Advanced Nursing; 57:339-350. doi:10.1111/j.1365-2648.2006.04089.x.

[12] Richard AA, Shea K. (2011). Delineation of self-care and associated concepts. Journal of Nursing Scholarship; 43:255-264.

[13] Prest, Melissa. (2013). "Mobile Phone Applications for Kidney Patients." Journal of Renal Nutrition 23.4 :e83-e85.

[14] National Kidney Foundation. (2002). K/DOQI Clinical Practice Guidelines for Chronic Kidney Disease: Evaluation, Classification and Stratification. Am J Kidney Dis. 39(suppl 1):S1-S75.

[15] Munro $\mathrm{HN}$ et al. (1987). Protein nutriture of a group of free-living elderly. Am J Clin Nutr 46: 586-592 
[16] FAO/WHO/UNU. (1985). Energy and protein requirements. Report of a Joint $\mathrm{FAO} / \mathrm{WHO} / \mathrm{UNU}$ Expert Consultation. WHO Technical Report Series no. 724. Geneva: OMS

[17] Rand WM et al. (2003). Meta-analysis of nitrogen balance studies for estimating protein requirements in healthyadults. Am J Clin Nutr 77: 109-127.

[18] Mitch WE (2002): Dietary requirements for protein and calories in the predialysis patient. In Handbook of Nutrition and the Kidney eds WE Mitch \& S Klahr, pp 135-156. Philadelphia, PA: Lippincott, Williams \& Wilkins.

[19] American Cancer Society. (2011). Global Cancer Facts and Figures.

[20] Lichtenstein, A.H., Appel, L.J., Brands, M., Carnethon, M., Daniels, S., Franch, H.A., Franklin, B., Kris-Etherton, P., Harris, W.S., Howard, B., Karanja, N., Lefevre, M., Rudel, L., Sacks, F., Van Horn, L., Winston, M., and Wylie-Rosett, J. (2006). Diet and Lifestyle Recommendations Revision: A Scientific Statement From the American Heart.

[21] Thomas, T. and Pfeiffer, A.F.H. (2012). Foods for the Prevention of Diabetes: How Do They Work? Diabetes/Metabolism Research and Reviews. 28(1). 25-49.

[22] Hurling, Robert, et al. (2007). "Using internet and mobile phone technology to deliver an automated physical activity program: randomized controlled trial." Journal of medical Internet research 9.2.

[23] Atkinson NL, Gold RS. (2002). The promise and challenge of eHealth interventions. Am $J$ Health Behav;26(6):494-503.

[24] Strecher VJ, McClure J, Alexander G, Chakraborty B, Nair V, Konkel J, et al. The role of engagement in a tailored web-based smoking cessation program: randomized controlled trial. J Med Internet Res 2008;10(5):e36.

[25] Jacobs N, Clays E, De Bacquer D, De Backer G, Dendale P, Thijs H, et al. (2011). Effect of a tailored behavior change program on a composite lifestyle change score: a randomized controlled trial. Health Educ Res;26(5):886-895.

[26] Glasgow RE, Nelson CC, Kearney KA, Reid R, Ritzwoller DP, Strecher VJ, et al. (2007). Reach, engagement, and retention in an Internet-based weight loss program in a multi-site randomized controlled trial. $\mathrm{J}$ Med Internet Res;9(2):e11.

[27] Cobb NK, Graham AL, Bock BC, Papandonatos G, Abrams DB. (2005). Initial evaluation of a real-world Internet smoking cessation system. Nicotine Tob Res Apr;7(2):207-216.

[28] Heesch KC, Mâsse LC, Dunn AL, Frankowski RF, Mullen PD. (2003). Does adherence to a lifestyle physical activity intervention predict changes in physical activity? J Behav Med;26(4):333-348.

[29] Leslie E, Marshall AL, Owen N, Bauman A. Engagement and retention of participants in a physical activity website. Prev Med 2005 Jan;40(1):54-59.

[30] Cooper Z, Fairburn CG, Hawker DM. (2004). Cognitive-behavioral Treatment of Obesity: A Clinician's Guide. New York, Guilford Press.

[31] Siek, K.A., Connelly, K.H., Rogers, Y., Rohwer, P., Lambert, D., and Welch, J.L. (2006). When Do We Eat? An Evaluation of Food Items Input into an Electronic Food Monitoring Application. IEEE Pervasive Health. 1-10.

[32] Siek, K.A., Connelly, K.H., and Rogers, Y. (2006). Pride and Prejudice: Learning How Chronically Ill People Think About Food. ACM Conference on Human Factors in Computing Systems (CHI). 947-950.

[33] Andrew, A. H., Borriello, G., \& Fogarty, J. (2013). Simplifying mobile phone food diaries: design and evaluation of a food index-based nutrition diary. In Proceedings of the 7th International Conference on Pervasive Computing Technologies for Healthcare (pp. 260-263). ICST (Institute for Computer Sciences, Social-Informatics and Telecommunications Engineering).

[34] Wantland DJ, Portillo CJ, Holzemer WL, Slaughter R, McGhee EM. (2004). The effectiveness of Web-based vs. non-Web-based interventions: a meta-analysis of behavioral change outcomes. J Med Internet Res;6(4):e40.

[35] Winters JM, (2007), Videoconferencing and telehealth technologies can provide a reliable approach to remote assessment and teaching without compromising quality. $\mathrm{J}$ Cardiovasc Nur;22:51-7.

[36] Kobb R, Hoffman N, Lodge R, Kline S. (2003). Enhancing elder chronic care through technology and care coordination: Report from a pilot. Telemed J E Health;9:18995 .

[37] Andrew, A. H., Borriello, G., \& Fogarty, J. (2013). Simplifying mobile phone food diaries: design and evaluation of a food index-based nutrition diary. In Proceedings of the 7th International Conference on Pervasive Computing Technologies for Healthcare (pp. 260-263). ICST (Institute for Computer Sciences, Social-Informatics and Telecommunications Engineering).

[38] Hollon, S. D., Stewart, M. O. \& Strunk, D. (2006). Enduring effects for cognitive behavior therapy in the treatment of depression and anxiety. Annual Review of Psychology 57, 285-315.

[39] Eysenbach G. (2005). The law of attrition. J Med Internet Res;7(1):e11. 
[40] Christensen H, Griffiths KM, Korten AE, Brittliffe K, Groves C. (2004). A comparison of changes in anxiety and depression symptoms of spontaneous users and trial participants of a cognitive behavior therapy website. J Med Internet Res Dec 22;6(4):e46.

[41] Farvolden P, Denisoff E, Selby P, Bagby RM, Rudy L. (2005). Usage and longitudinal effectiveness of a Web-based self-help cognitive behavioral therapy program for panic disorder. J Med Internet Res;7(1):e7

[42] Couper MP, Alexander GL, Zhang N, Little RJ, Maddy N, Nowak MA, et al. Engagement and retention: measuring breadth and depth of participant use of an online intervention. J Med Internet Res 2010;12(4):e52.
[43] Wicks P, Massagli M, Frost J, Brownstein C, Okun S, Vaughan T, Bradley R, Heywood J. (2010). Sharing Health Data for Better Outcomes on PatientsLikeMe, J Med Internet Res;12(2):e19.

[44] Cooper Z, Fairburn CG, Hawker DM. (2004). Cognitive-behavioral Treatment of Obesity: A Clinician's Guide. New York, Guilford Press.

[45] Siek, K.A., Connelly, K.H., and Rogers, Y. (2006). Pride and Prejudice: Learning How Chronically Ill People Think About Food. ACM Conference on Human Factors in Computing Systems (CHI). 947-950. 